RASĀYAN J. Chem.

Vol. 13 | No. 3 |2010-2019| July - September | 2020 ISSN: 0974-1496 | e-ISSN: 0976-0083 | CODEN: RJCABP http://www.rasayanjournal.com http://www.rasayanjournal.co.in

\title{
THE CHANGES OF CHEMICAL COMPOSITION AND ANTIOXIDANT ACTIVITY OF COCONUT SAP DURING HEATING PROCESS
}

\author{
P. Haryanti ${ }^{1}{ }^{*}$, Supriyadi ${ }^{2}$, D.W.Marseno ${ }^{2}$ and U.Santoso ${ }^{2}$ \\ ${ }^{1}$ Department of Agricultural Technology, Jenderal Soedirman University, Purwokerto, Indonesia \\ ${ }^{2}$ Department of Food and Agricultural Product Technology, Gadjah Mada University, \\ Yogyakarta, Indonesia \\ *E-mail: pepita.haryanti@unsoed.ac.id
}

\begin{abstract}
Maillard reaction may lead to the forming of the brown color of granulated coconut sugar during sap heating. It has been proven that Maillard reaction products (MRPs) have antioxidant activity. It is, thus, necessary to verify that the Maillard reaction occurs during the heating of the sap. This verification would be valuable to figure out the antioxidant potency of granulated coconut sugar in future studies. Reducing sugar as well as free amino acid content of the sap decreased in the first 10 min of heating from 3.78 to $1.73 \% \mathrm{db}$ and from 0.09 to $0.04 \% \mathrm{db}$, respectively. About $77.98 \%$ of free amino acid levels of the coconut sap decreased. Such reduction was an indicator of the occurrence of the carbonyl-amino reaction, which was deemed as the initial Maillard reaction. The reaction was also demonstrated by the absorption band at $1635.64 \mathrm{~cm}^{-1}$ denoting the presence of $\mathrm{C}=\mathrm{O}$ which could correspond to Amadori compounds evaluated by FTIR. The Maillard reaction occurred during the heating process of sap resulting in the increase of antioxidant activity evaluated by the DPPH method and $\mathrm{Fe}^{2+}$ chelating activity. This increase might be due to the reductone compounds formation at the intermediate Maillard reaction.
\end{abstract}

Keywords: Coconut sap, Maillard Reaction, Reducing Sugar, Free Amino Acid, Granulated Coconut Sugar, Antioxidant Activity.

(C) RASĀYAN. All rights reserved

\section{INTRODUCTION}

The browning in food is a type of non-enzymatic reactions which commonly occurs during food processing and storage. Three browning reactions tend to exist in foods such as ascorbic acid oxidation, caramelization and Maillard reaction. Such reactions can significantly influence food production as well as affect typical flavor, color and aroma of the food. ${ }^{1,2}$ Furthermore, the interaction between reducing sugar and derived amino group, which is usually from protein or amino acid, can lead to the occurrence of the Maillard reaction. Maillard reaction is commonly started by the carbonyl-amino reaction. In this reaction, the $\alpha$-amino groups of amino acids or proteins are condensed with the carbonyl groups of reducing sugars. This reaction may occur if the $\mathrm{pH}$ value of the substance is bigger than the isoelectric point of the amino group. The next step is the creation of Maillard reaction products (MRPs). MRPs are valuable compounds during the Maillard reaction. The last step on Maillard reaction is the form of brown product which is called melanoidin. ${ }^{3}$

Granulated coconut sugar is produced from coconut sap which is taken by tapping of the young inflorescence of coconut flowers during a certain period. Coconut sap is typically sugary and has oysterwhite in color. Also, this translucent substance commonly has about neutral $\mathrm{pH} .{ }^{4}$ This substance contains nutritious components, such as sugar, proteins, vitamins, and minerals. Coconut sap is usually processed further into drinks or sugar.

The brown color is generally used as a common feature to assess the quality of coconut sugar. The browning usually presents during sap heating which is normally caused by Maillard reaction. The amount of Maillard reaction is mostly affected by the reactants contained in sap, such as reducing sugar and amino acids, ${ }^{5}$ as well as the temperature of the heating process. ${ }^{6}$ Furthermore, in Maillard reaction amino acid as well as reducing sugar usually bring significant contributions to the development of color as well Rasayan J. Chem., 13(3), 2010-2019(2020) http://dx.doi.org/10.31788/ RJC.2020.1335443

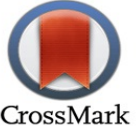


RASĀYAN J. Chem.

Vol. 13 | No. 3 |2010-2019| July - September | 2020

as flavor and antioxidant in food. ${ }^{7}$ Numerous publications reported that antioxidants may be potentially found in Maillard reaction products (MRPs) either from the amino-sugar model or in food products. In vitro studies demonstrated that MRPs have roles as metal chelators as well as radical scavengers ${ }^{8,9}$ and inhibition on lipid peroxidation in a linoleic acid emulsion, ${ }^{10}$ so that they may have antioxidant activity. Moreover, MRPs obtained from the chitooligosaccharide and glycine model system provided high antioxidant activity. ${ }^{11}$

Studies on coconut sugar, especially its antioxidant activity have been reported by Karseno et al. ${ }^{12}$ The study informed that there was a significant correlation between brown color derived from Maillard reaction and antioxidant activity of coconut sugar. Hence, it is essential to verify the occurrence of the Maillard reaction during the heating of coconut sap in the coconut sugar preparation. The verification of the Maillard reaction that occurs during coconut sugar processing will become a valuable reference for further research regarding the coconut sugar potency as a source of an antioxidant compound derived from Maillard reaction. This research aimed to figure out the changes of chemical properties as well as the antioxidant activity of coconut sap at the beginning of heating of sap as an indicator of Maillard reaction.

\section{Material and Methods}

\section{EXPERIMENTAL}

The coconut sap was obtained by tapping young coconut flowers (inflorescences) of coconut trees (Cocos nucifera, L.) which was located at Sikapat Village Banyumas Regency Indonesia (500 to 1,000 meters above sea level). Coconut sap tapping was undertaken during the daytime under relatively fine weather. Air temperature and relative humidity during tapping ranged about $24-27{ }^{\circ} \mathrm{C}$ and $91-92 \%$, respectively. Chemicals used in this research were similar as used in those conducted by Sulistyo and Haryanti. ${ }^{13}$

\section{General Procedure}

Ten coconut trees were picked as sources of coconut sap used in this research. During tapping, coconut sap was collected in several plastic containers that had been cleaned in advance using hot water. The selected preservatives ${ }^{14}$ i.e. a mix of $1.7 \mathrm{~g} / \mathrm{L}$ of lime and $0.56 \mathrm{~g} / \mathrm{L}$ mangosteen peel was subsequently added into each container. The tapping procedure was undertaken by firstly cutting the tip of coconut inflorescences, and then a plastic container that has been added to the preservative was set up on to inflorescence with the cut filled in the container. The tapping process was carried out for $9 \mathrm{~h}(06.00 \mathrm{am}-03.00 \mathrm{pm})$. To preserve its quality, the collected coconut sap was stored in a cool box with a temperature of around $4{ }^{\circ} \mathrm{C}$.

Afterward, a volume of $2.5 \mathrm{~L}$ of sap was purified using a filter cloth. The clean sap was then poured into an aluminum pan and subsequently heated and stirred up for about $90 \mathrm{~min}$. Twenty milliliters of sap samples were collected every 10 min during heating treatment. The sap samples were filled in a glass vial then cooled immediately to discontinue the chemical reaction in the coconut sap. The chemical and antioxidant properties of the sap samples were then analyzed.

\section{Detection Methods}

\section{Reducing Sugar and Sucrose Content}

Reducing sugar was determined by the procedure of Miller ${ }^{15}$ with a slight modification. Firstly, a mixture of one gram of coconut sap sample and five milliliters of distilled water was prepared. A volume of three milliliters of the mixture was then pipetted into a test tube. Subsequently, a volume of three milliliters of $1 \%$ 3,5-dinitrosalicylic acid reagent was mixed and the mixed solution was afterward heated up to $90{ }^{\circ} \mathrm{C}$ in a water bath for $15 \mathrm{~min}$. The next step was the addition of $1 \mathrm{~mL}$ of potassium tartrate $40 \%$ for stabilizing the mixture color. The mixed solution was then rested under room temperature for $5 \mathrm{~min}$. Its spectrum absorbance at $540 \mathrm{~nm}$ was subsequently determined. Furthermore, to quantify the sample, a standard glucose solution was utilized.

To determine coconut sap total sugar, the hydrolysis method was applied. The hydrolysis process was conducted by incubating the sample with three milliliters of $\mathrm{HCl} 25 \%$ at a temperature of $70{ }^{\circ} \mathrm{C}$ for 10 min. Under room temperature, the mixed solution was subsequently cooled and neutralized using $\mathrm{NaOH}$ $45 \%$. A $3.0 \mathrm{~mL}$ of the sample was then collected to determine sap reducing sugar. Eventually, the sucrose content was determined by subtracting reducing sugar from total sugar. 
RASĀYAN J. Chem.

Vol. 13 | No. 3 |2010-2019| July - September | 2020

\section{Sugar Composition}

Sugars composition was identified by high-performance liquid chromatography (HPLC) Knauer Smartline Pump 1000. Fifty milligrams of dried coconut sap filled in a test tube. The sap was then dissolved by $2 \mathrm{~mL}$ of $\mathrm{H}_{2} \mathrm{O}$. The mixture was subsequently stirred for 1 min and was sonicated for 10 min. The sap was added with $\mathrm{H}_{2} \mathrm{O}$ until the volume of the mixture reached $5 \mathrm{~mL}$ in a volumetric flask and was centrifuged afterward at $8,000 \mathrm{~g}$ for $5 \mathrm{~min}$ (Thermo Scientific; Carlsbad, CA, USA). The supernatant was removed from a test tube and was filtered with millex $0.45 \mu \mathrm{m}$. The optimum condition for HPLC was set as follows: $5 \mu \mathrm{L}$ of diluted sample was injected to Metacharb 87C column $(300 \times 6.5 \mathrm{~mm})$ and was then eluted by $\mathrm{H}_{2} \mathrm{O}$ at $0.6 \mathrm{~mL} /$ minutes flow with an oven temperature of $85^{\circ} \mathrm{C}$ and was subsequently detected by G 1362 A Refractive index (RI) detector. The sugar concentrations used as standards were 50,100,200,500, 1000 and $2000 \mathrm{ppm}$ for each fructose and glucose, then injected for $20 \mu \mathrm{L}$. The sugars concentration of the sap, eventually, was calculated by an external standard.

\section{Total Free Amino Acid Content}

Total free amino acid content was determined using the method conducted by Yao et al. ${ }^{16}$ One gram of coconut sap was placed in a $25 \mathrm{~mL}$ volumetric flask and added with $0.5 \mathrm{~mL}$ of a buffer solution with $\mathrm{pH}$ of 8 and $0.5 \mathrm{~mL}$ of ninhydrin solution. In a boiling water bath, the flask was then heated for $15 \mathrm{~min}$. Under room temperature, it was subsequently cooled for $5 \mathrm{~min}$. A volume of $25 \mathrm{~mL}$ of distilled water was added to with the mixture afterward. The measurement of the diluted solution light absorbance at $570 \mathrm{~nm}$ was performed using Genesys 10S UV-Vis spectrophotometer (Thermo Scientific). To quantify the samples, we utilize glutamic acid for preparing the standard curve.

\section{Free Amino Acids Composition}

Ten milliliters of sap were firstly centrifuged at $2054 \mathrm{~g}$ and the supernatant was then filtered by using a $0.45 \mu \mathrm{m}$ nylon filter membrane. The composition of coconut sap free amino acid was ascertained using the method undertaken by Wang et al. ${ }^{17}$ According to the procedure, a mixture of $140 \mu \mathrm{L}$ of sample infusion (or standard amino acid) and $20 \mu \mathrm{L}$ OPA solution was incubated at $25^{\circ} \mathrm{C}$ for $2 \mathrm{~min}$. This mixture was used immediately for HPLC analysis. The OPA-based derivatization was conducted according to the modified procedure performed by Thippeswamy et al. ${ }^{18}$ To determine the free amino acids of the sap, we utilized the Shimadzu LC 10AD HPLC system equipped with UV detector (Shimadzu Technologies, Kyoto, Japan). The measurement was completed on a Licrospher Lichrocart C18 column (125x $4.6 \mathrm{~mm}, 5$ $\mu \mathrm{m}$, Merck, Darmstadt, Germany) at a flow rate of $1.0 \mathrm{~mL} / \mathrm{min}$. The free amino acids were monitored at $\lambda$ $338 \mathrm{~nm}$, the injection volume was $100 \mu \mathrm{L}$. Each amino acid was identified and calculated by the calibration curve of the amino acids mix solutions relative to external standards. Each amino acid content was expressed as mg per $\mathrm{kg}$ of the sample. The typical chromatogram of standard amino acids is shown in Fig.-1.

\section{Total Phenolic}

Measurement of coconut sap total phenolic was carried out based on the Folin-Ciocalteu method with a slight modification. ${ }^{19}$ Firstly, we mixed $300 \mu \mathrm{L}$ of sap sample with $1.5 \mathrm{~mL}$ of $10 \%$ Folin-Ciocalteu reagent in a test tube. The mixed solution was then incubated for $8 \mathrm{~min}$. Subsequently, a volume of 1.2 $\mathrm{mL}$ of $7.5 \% \mathrm{Na}_{2} \mathrm{CO}_{3}$ which had been dissolved in distilled water was mixed to the solution. The mixed solution was afterward incubated at $30^{\circ} \mathrm{C}$ for $1 \mathrm{~h}$, and the measurement of spectrum absorbance at a wavelength of $765 \mathrm{~nm}$ was then undertaken. For measuring the blank, a similar procedure was performed by replacing the sample with an appropriate solvent. The result was reported as absorbance in the standard curve of gallic acid that was applied as the basic phenolic compound.

\section{Browning Intensity}

The browning measurement of coconut sap during heating was conducted by referring to the procedure performed by Sulistyo and Haryanti. ${ }^{13}$ 
RASĀYAN J. Chem.

Vol. 13 | No. 3 |2010-2019| July - September | 2020

\section{DPPH Radical Scavenging Activity (RSA)}

Coconut sap RSA was determined with radical DPPH method. ${ }^{19}$ A volume of $2.8 \mathrm{~mL}$ of $0.1 \mathrm{mM}$ DPPH methanolic solution was mixed with $200 \mu \mathrm{L}$ of sap sample in a test tube, while the blank sap sample was replaced with solvent. The mixture was then incubated at $30{ }^{\circ} \mathrm{C}$ for $30 \mathrm{~min}$, and subsequently, its spectrum absorbance at $515 \mathrm{~nm}$ was measured using Genesys 10S UV-Vis spectrophotometer (Thermo Scientific). The antioxidant activity was expressed as a percentage of RSA according to the following formula:

$$
R S A(\%)=\frac{(A 0-A s)}{A 0} \times 100
$$

Where, Ao and As are spectrum absorbance at $515 \mathrm{~nm}$ of the blank and sample, respectively, after 30 $\min$.

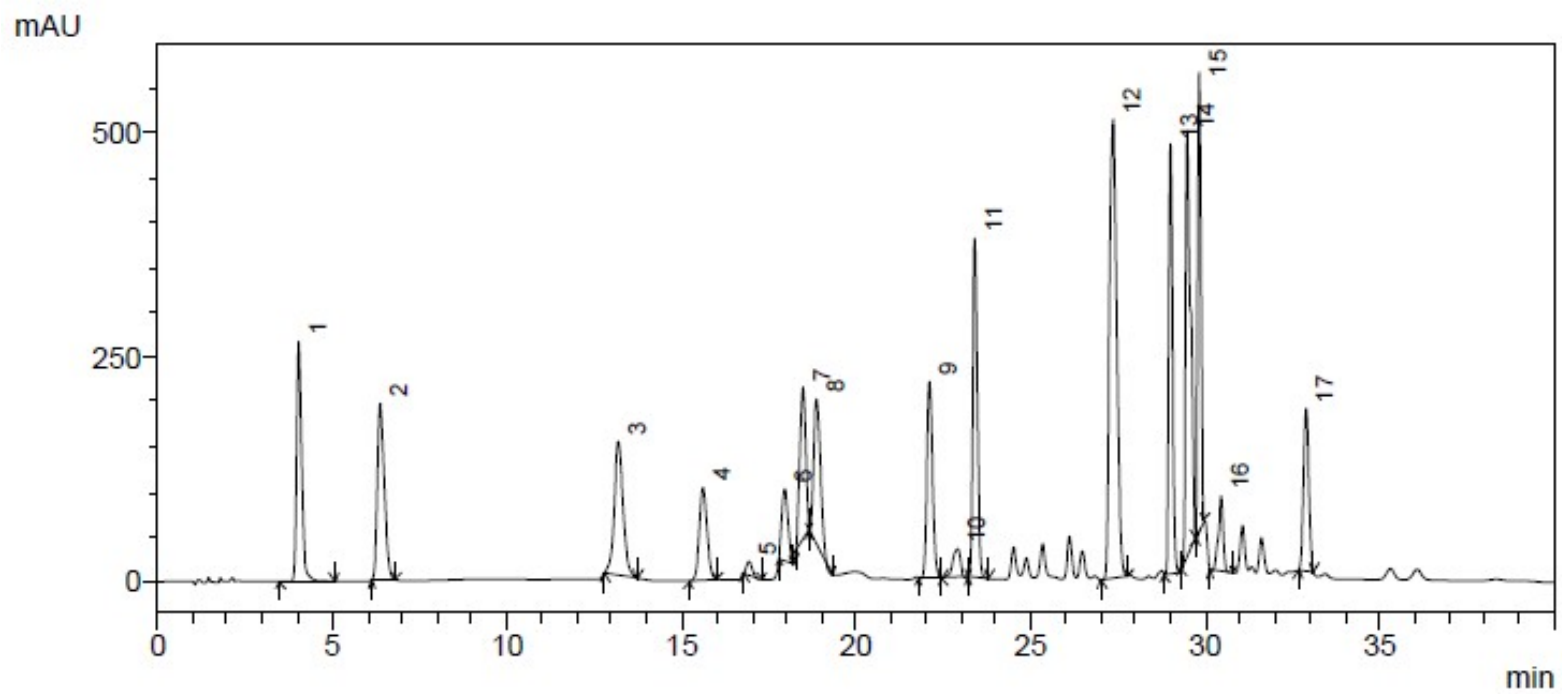

Fig.-1: HPLC Chromatograms of Free Amino Acid Standard Mix Solution 1. L-asp Acid; 2. L-glu Acid; 3. L-pro; 4. L-ser; 5. L-his; 6. L-arg; 7. L-gly; 8. L-thr; 9. L-ala; 10. L-val; 11. L-tyr; 12. L-met; 13. L-phe; 14. L-ile; 15. L-leu;

\section{Chelating Activity} 16. Cys; 17. L-lys

The chelating activity of the sap indicates the ability of sap to chelate metal ions $\mathrm{Fe}^{2+}$. This feature was determined according to the procedure conducted by Kim. ${ }^{8,9}$ An amount of $1.0 \mathrm{~g}$ of sap sample with fivefold dilution was firstly prepared. Subsequently, a volume of $100 \mu \mathrm{L}$ of the sap solution was mixed with $600 \mu \mathrm{L}$ of distilled water and $100 \mu \mathrm{L}$ of $0.2 \mathrm{mM} \mathrm{FeCl}_{2} \cdot 4 \mathrm{H}_{2} \mathrm{O}$. The mixture was then rested under room temperature for $30 \mathrm{~s}$. A volume of $200 \mu \mathrm{L}$ of $1 \mathrm{mM}$ ferrozine was then added to the mixture and its spectrum absorbance at $562 \mathrm{~nm}$ was determined using Genesys 10S UV-Vis spectrophotometer (Thermo Scientific) after being rested for $10 \mathrm{~min}$ under room temperature. In the meanwhile, a similar mixture of $100 \mu \mathrm{L}$ of distilled water, was utilized as the control. The $\mathrm{Fe}^{2+}$ chelating activity was assessed using the following formula:

$$
\text { Chelation activity }(\%)=\frac{A o-A s}{A o} \times 100
$$

Where Ao and As are spectrum absorbance at $562 \mathrm{~nm}$ of the blank and sample, respectively, after $10 \mathrm{~min}$ of incubation.

\section{Chemical Structural Analysis}

Chemical structural analysis of the coconut compound during heating treatment was evaluated through functional groups of sap compounds by Fourier transformation infrared (FTIR) spectroscopy. FTIR measurements were performed using an FTIR analyzer (IRPrestige-21, Shimadzu, Japan) within the range of $250-4,000 \mathrm{~cm}^{-1}$. 
RASĀYAN J. Chem.

Vol. 13 | No. 3 |2010-2019| July - September | 2020

\section{Statistical Analysis}

Chemical properties and antioxidant activity data were reported as mean \pm standard deviation (SD), and statistically analyzed using SPSS (version 20.0; IBM Corp., US). Analysis of variance (ANOVA) and Duncan's multiple range tests were used to assess the significance of differences among means, which was considered at $P<0.05$.

\section{RESULTS AND DISCUSSION}

\section{Reducing Sugar, Total Free Amino Acid and Sucrose Content}

The reducing sugar, total free amino acid and sucrose content of coconut sap during heating is shown in Fig.-2.

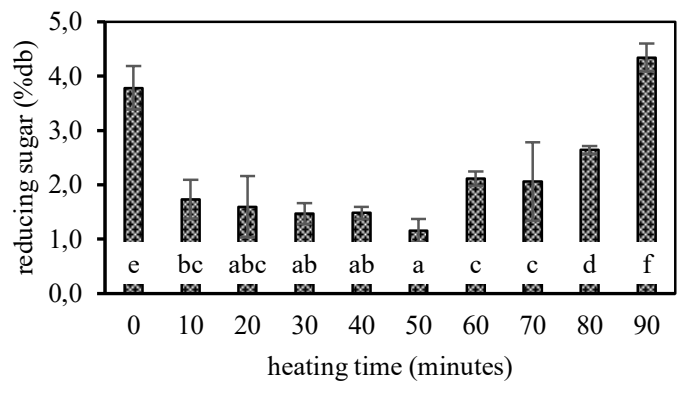

(A)

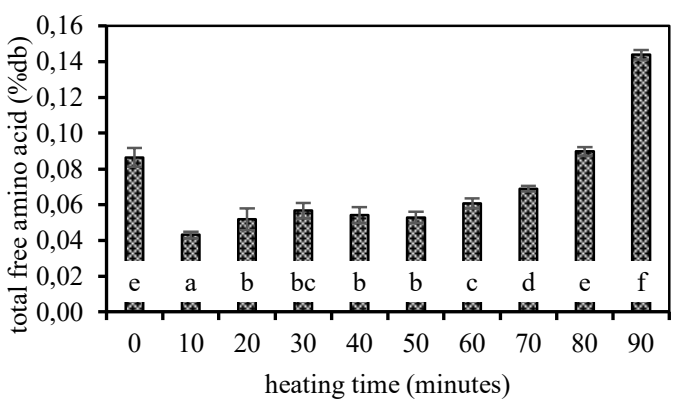

(B)

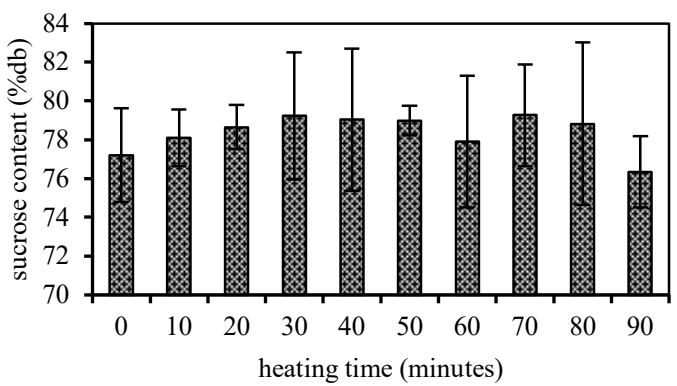

(C)

Note: Different small letters inside the bars indicate the significant difference during the heating time of coconut sap $(\mathrm{P}<0.05)$

Fig.-2: The Reducing Sugar (A), Total Free Amino Acid (B) and Sucrose Content (C) of Coconut sap during the Heating Process

Based on Fig.-2(A, B), during 10 min of heating, the reducing sugar and free amino acids was decreased significantly. The decline still occurred until $50 \mathrm{~min}$ of heating with smaller slopes. The reduction of reducing sugar and amino acids at the beginning of coconut sap heating was caused by Maillard reaction. According to Eskin and Shahidi, ${ }^{2}$ the reaction of Maillard begins with the reaction between the carbonyl group on the reducing sugar and the amine group in the amino acid. A high percentage of moisture content $(83.65 \%)$ still presents in coconut sap at the initial heating process. This condition is important in generating the essential reactants especially free ammonia or nitrogen and dicarbonyl compounds through retro-aldol and deamination reaction. Moreover, the presence of moisture would increase the possibility of reactants interaction. According to Ho et $\mathrm{al}^{20}{ }^{20}$, monosaccharide such as glucose and fructose commonly contribute to the initial step of Maillard reaction by creating a plentiful group of high reactive $\mathrm{C} 2, \mathrm{C} 3$ and C4 dicarbonyl compounds.

Figure-2(C) shows that the heating of sap up to 90 min affects the amount of sucrose content slightly decrease. During sap heating, its temperature increased and reached about $101.4{ }^{\circ} \mathrm{C}$ at $90 \mathrm{~min}$. Such conditions resulted in the occurrence of hydrolysis of sucrose slowly. According to Ashrafi et al. ${ }^{21}$, sucrose needed a presence of hydrochloric acid or invertase $\mathrm{e}^{22,23}$ as a catalyst to experience hydrolysis. Ho 
RASĀYAN J. Chem.

Vol. 13 | No. 3 |2010-2019| July - September | 2020

et al. ${ }^{20}$ reported that sucrose concentration showed an extreme reduction during the first $180 \mathrm{~min}$ of heating and tended to a constant concentration afterward.

\section{Reducing Sugar and Free Amino Acids Composition}

The glucose and fructose content of coconut sap during heating is shown in Fig.-3(A).

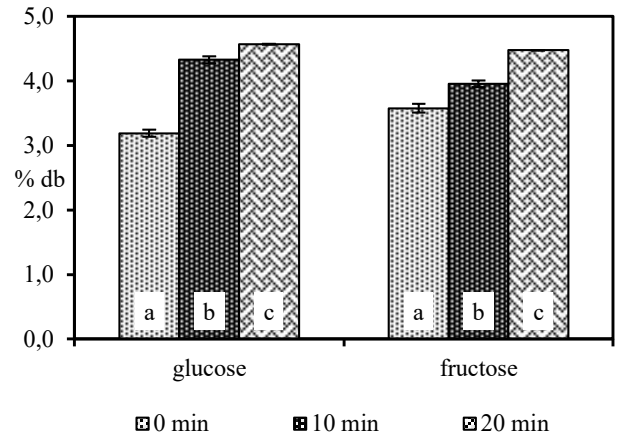

(A)

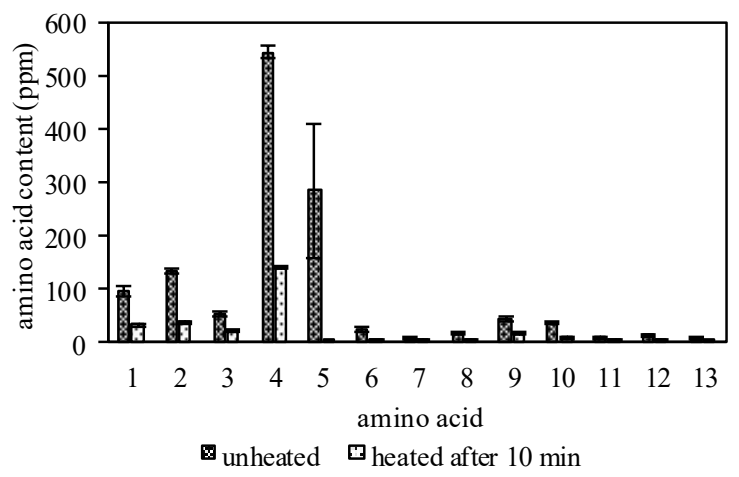

(B)

Note: Different small letters inside the bars in the same parameter indicate the significant difference during the heating time of coconut sap $(\mathrm{P}<0.05)$

Fig.-3: Reducing Sugar Composition of Coconut sap during Heating Treatment (A) and Free Amino Acid Composition of Unheated Coconut sap and after heated of 10 min evaluated by HPLC (B). 1. L-asp acid; 2. L-glu acid; 3. L-pro; 4. L-ser; 5. L-his; 6. L-gly; 7. L-thr; 8. L-ala; 9. L-val; 10. L-tyr; 11. L-met; 12. L-phe; 13. L-lys

Before the heating process, the fructose content of coconut sap was significantly higher $(3.58 \% \mathrm{db})$ than glucose content $(3.19 \% \mathrm{db})$. However, after $10 \mathrm{~min}$ of heating, the fructose content of coconut sap was significantly lower $(3.96 \% \mathrm{db})$ than the glucose $(4.33 \% \mathrm{db})$, while after heating time of $20 \mathrm{~min}$, the fructose and glucose contents were not significantly different. The initial stage of Maillard reaction provides the carbonyl groups for being in contact with the free amino groups of amino acids, peptides and proteins. The initial reaction rate relies on the rate whereupon the sugar ring opens to the oxo or reducible form. Moreover, the concentration of the sugar increases along with the increase of its $\mathrm{pH}$.

Fructose was more reactive in the initial heating process of coconut sap than glucose. Eskin and Shahidi²; Kim and Lee ${ }^{24}$ reported that the browning rate of fructose was much faster than that of glucose during the browning initial stage, however, it runs slower at the next stage. The browning rate of the fructose system was higher than the glucose system during the first period, but then the opposite condition occurred during the successive stage. In comparison with the fructose system, the difference in losses was ascribed to the greater polymerization of the melanoidins derived from glucose. The slight increase in reducing sugar such as glucose and fructose during the initial heating might because of the degradation of sugar. According to Cammerer et al. ${ }^{25}$, the carbohydrates hydro-thermolytic degradation under aqueous reaction conditions led to more reactive monosaccharide formation.

Figure-3(B) shows that the free amino acid composition of coconut sap comprises aspartic acid (94.63 ppm), glutamic acid (133.09 ppm), proline $(51.61 \mathrm{ppm})$, serine $(544.05 \mathrm{ppm})$, histidine $(284.45 \mathrm{ppm})$, glycine $(24.51 \mathrm{ppm})$, threonine $(6.93 \mathrm{ppm})$, alanine $(16.36 \mathrm{ppm})$, valine (44.67), tyrosine (35.76 ppm), methionine $(10.42 \mathrm{ppm})$, phenylalanine $(14.87 \mathrm{ppm})$ and lysine $(6.67 \mathrm{ppm})$. The heating process for 10 min caused a decrease in about $77.98 \%$ of free amino acid levels of the coconut sap from 1268.02 to $279.21 \mathrm{ppm}$. The free amino acids have reactive amine groups reacted with the carbonyl group of reducing sugars. The polar side chain of amino acid on coconut sap, i.e serine, threonine, histidine and lysine, may have a main role in Maillard reaction by giving nitrogen atom sources. According to Ho et al. ${ }^{20}$ the basic feature of these amino acids was having stronger activity during Maillard reaction if compared to other amino acids. Eskin and Shahidi ${ }^{2}$ reported that under basic conditions, the amino acid undergoes deprotonation, the amine group becomes reactive and then reacted with carbonyl groups of the 
RASĀYAN J. Chem.

Vol. 13 | No. 3 |2010-2019| July - September | 2020

reducing sugar. The reaction is called the carbonyl-amino reaction which is the initial stage of Maillard reaction.

\section{Chemical Structure by FTIR Spectroscopy}

IR spectra of coconut sap at the initial stage of heating is shown in Fig.-4.

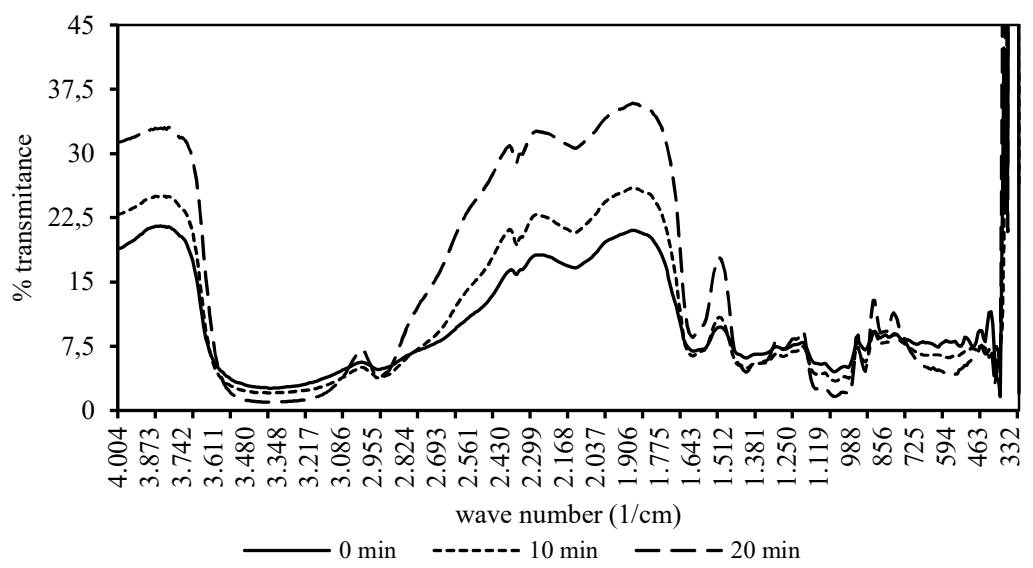

Fig.-4: FTIR Pattern of Coconut sap during the Heating Process

Figure-4 shows the FTIR spectra of coconut sap during heating for 0,10 , and $20 \mathrm{~min}$. The absorption bands of $2121.70 ; 2360.87 ; 2931.80$, and $2279.29 \mathrm{~cm}^{-1}$ correspond to the presence of $-\mathrm{OH}$ groups. Fernandez et al. ${ }^{26}$; Kambatyrov et al. ${ }^{27}$ reported the bands of $2000-3500 \mathrm{~cm}^{-1}$ indicates the presence of OH groups. FT-IR spectra of MRPs of chitooligomer showed there were characteristic absorption bands between 4000 and $2500 \mathrm{~cm}^{-1}$ for $-\mathrm{OH}\left(3350 \mathrm{~cm}^{-1}\right)$ and $-\mathrm{NH}\left(3280 \mathrm{~cm}^{-1}\right){ }^{10}$ The N-H span, which is an indicator of the amine group, appears in the wavenumber ranged of $3500-3300 \mathrm{~cm}^{-1}$ coinciding with the $\mathrm{OH}$ group.

The specific group $-\mathrm{C}=\mathrm{O}$ (carbonyl) occurred at the wavenumber of $1635.6 \mathrm{~cm}^{-1}$ indicates the presence of amide in sap. Jung et al. ${ }^{10}$ reported that the absorption band at $1649 \mathrm{~cm}^{-1}$ in MRPs of chitooligomer is attributed to amide I. According to Fernandez et al. ${ }^{26}$, the absorption bands ranged from $1750-1500 \mathrm{~cm}^{-1}$, expressing the presence of $\mathrm{C}=\mathrm{N}, \mathrm{C}-\mathrm{NH}, \mathrm{C}=\mathrm{O}$, and $\mathrm{C}=\mathrm{C}$ which relate to Schiff bases, Amadori compounds, and reductone respectively.

\section{Total Phenolic and Browning Intensity}

The total phenolic and browning intensity of coconut sap during heating are shown in Fig.-5. Based on Fig.-5(A) the total phenolic content of the sap decreased significantly during heating for the first $10 \mathrm{~min}$. After that, the total phenolic tended to decrease until $40 \mathrm{~min}$ of heating but then escalated until $90 \mathrm{~min}$ of warming. The total phenolic decline in the early heating was due to the formation of quinones. According to Buchner et al. ${ }^{28}$; Rohn et al. ${ }^{29}$, during the heating process, phenolic compounds can be easily oxidized non enzymatically. The formation of quinones will lead to degradation products that may act as substrates for the next reaction such as polymerization, hydration, and disproportionation. Furthermore, the alkaline $\mathrm{pH}$ of coconut sap supported the formation of quinones more rapidly. Phenolic compounds being highly susceptible to oxidation. ${ }^{29}$ The heating treatment of $50 \mathrm{~min}$, showed an increase in phenolic content. The increment of a phenolic compound may be caused by Maillard reaction. According to Brudzynski and Miotto $^{30}$, heat treatment caused an increase in the integration of phenolic compounds during the formation of melanoidins in honey.

Figure-5(B) depicts the browning intensity of coconut sap during heating. The color of coconut sap was getting darker along with the increasing heating time. As seen in Fig. 5(B) the absorbance increase from 0.058 at the first $10 \mathrm{~min}$ of processing time to 0.155 after $90 \mathrm{~min}$ of the heating process. Sugar structure in sap, in the form of mono, oligo, or polysaccharide, as well as its interaction level with amino groups contributed to the color formation of the coconut sap. The browning color is related with Maillard 
RASĀYAN J. Chem.

Vol. 13 | No. 3 |2010-2019| July - September | 2020

reaction according to the free ammonia compounds creation from amino acid degradation which might be participated in the browning. ${ }^{20}$ The initial $\mathrm{pH}$ of the coconut sap was also contributed to the browning intensity of sap during heating treatment. Coconut sap used in the study had a $\mathrm{pH}$ value of 8.4. According to Karseno et al., ${ }^{12}$ the alkali $\mathrm{pH}$ of coconut sap will rise the brown color of coconut sugar, therefore it indicated that the browning reaction occurred during heating treatment also increased.

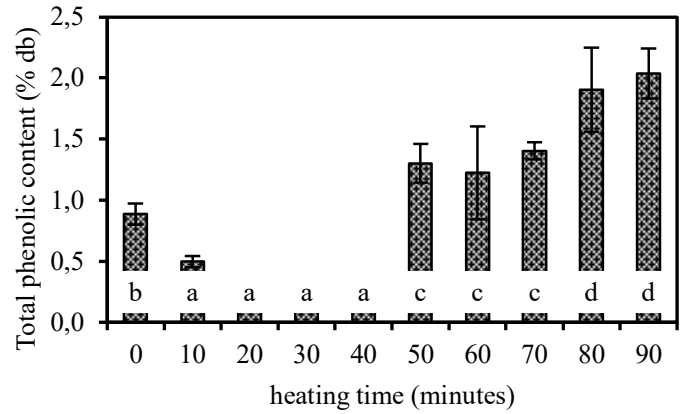

(A)

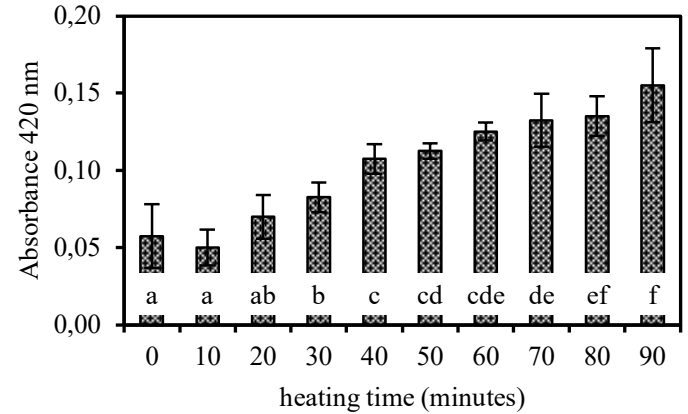

(B)

Note: Different Small Letters inside the Bars indicate the Significant Difference during the Heating Time of Coconut sap $(\mathrm{P}<0.05)$

Fig.-5: The Change of Total Phenolic of Coconut sap (A) and Browning Intensity (B) during Heating

\section{DPPH and Chelating Methods Based on Antioxidant Activity}

The antioxidant activity by both DPPH and chelating methods of coconut sap during heating are shown in Fig.-6.

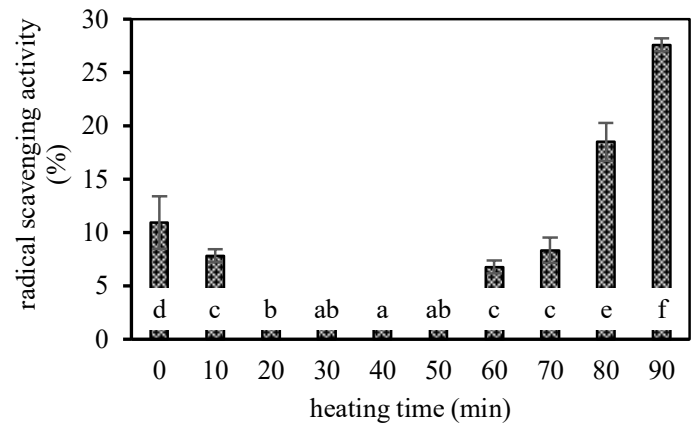

(A)

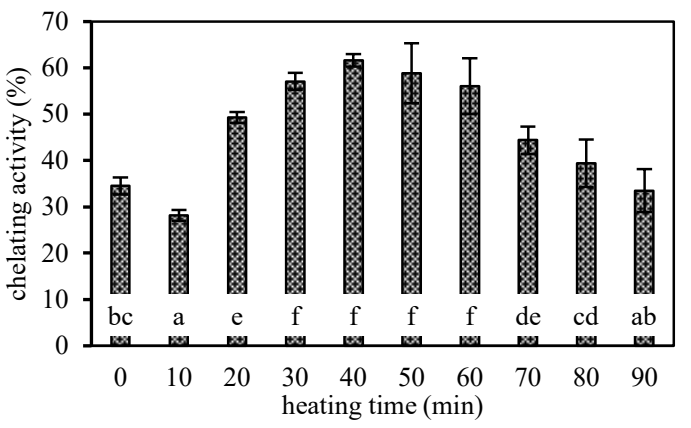

(B)

Note: Different Small Letters inside the Bars indicate the significant difference during the heating time of coconut sap $(\mathrm{P}<0.05)$

Fig.-6: The Change of DPPH RSA (A) and $\mathrm{Fe}^{2+}$ Chelating Activity (B) of sap during Heating

Based on Fig.-6(A), the antioxidant activity of the sap by both radical scavenging and chelating activity decreased significantly during heating for the first $10 \mathrm{~min}$. This degradation was supported by the decrease of total phenolic at the beginning of heating. There was a significant positive correlation for total phenolic to radical scavenging activity (RSA) of sap with r-value of 0.764 . According to Pellati et al. ${ }^{31}$; Atun et al., ${ }^{32}$ phenolic compounds contribute to antioxidant activity. The antioxidant activity of the phenolic compounds turned down as a result of the covalent attachment to the protein. ${ }^{29}$

The radical scavenging activity (RSA) of coconut sap declined until 50 min of heating. After that, the longer duration of heat treatment led to the increasing of RSA of sap. Chemical reactions, such as Maillard reaction at early and intermediate stages, may occur during the heating process. A high correlation was shown between the DPPH radical scavenging activity on the MRPs after $24 \mathrm{~h}$ heating and the contents of total phenolic with $r=0.8833 . .^{5}$ It suggested that the melanoidins, one of the MRPs, gave a contribution to raising the activities during heating. The Maillard reaction at the intermediate stage 2017 
RASĀYAN J. Chem.

Vol. 13 | No. 3 |2010-2019| July - September | 2020

produces compounds in which one of them is reductone that has antioxidant properties. ${ }^{33}$ The Maillard reaction products and melanoidin contained a phenolic compound that was incorporated during heating treatment. ${ }^{30}$ Moreover, the increment of the RSA might be caused by the increment of the browning intensity of coconut sap during the heating process. Browning intensity and RSA of sap had a significant correlation with r-value of 0.507 . According to Gomez-Ruiz et al. ${ }^{34}$; Morales and Perez. ${ }^{35}$ there is a strong linearship between the color intensity of melanoidin with radical peroxyl scavenging. Also, Karseno et al. ${ }^{12}$ also reported that browning intensity and DPPH RSA had a significant correlation with $\mathrm{r}$ value of 0.93 .

The $\mathrm{Fe}^{2+}$ chelating activity of coconut sap decreased at 10 min of heating process (Fig.-6B). It is well known that the thermal processes such as boiling and frying can reduce the phenolic substance. According to Buchner et al., ${ }^{28}$ the ortho-dihydroxy structure or catechol structure of the phenolic compound is responsible for donating protons and also for the chelation of metal ions. However, the $\mathrm{Fe}^{2+}$ chelating activity of coconut sap increased after $20 \mathrm{~min}$ of heating. At this period, the intermediate of Maillard reaction may occur and produce MRPs. According to Nursten ${ }^{3}$ the MRPs reduced the pro-oxidant activity of the copper, whereas, chelating with copper may have resulted in an increased ability to donate hydrogen to the DPPH radical. In vitro studies revealed that MRPs may exhibit essential healthpromoting activity as they have potential as metal chelators. ${ }^{36}$

\section{CONCLUSION}

The first 10 min of heating, the decrease of reducing sugar and free amino acid in coconut sap indicated the occurring of carbonyl-amino reaction. Fructose was more reactive in the initial stage of a browning reaction during the heating of coconut sap than glucose. All of the free amino acid compounds in coconut sap decreased at the initial heating based on HPLC analysis. Also, the presence of band ranged from $1750-1500 \mathrm{~cm}^{-1}$ indicated the presence of Schiff bases, Amadori compounds and reductone. Moreover, the increase of browning intensity and total phenolic content at $50 \mathrm{~min}$ of heating might cause the formation of MRPs. The antioxidant activity at the initial heating decreased. However, the radical scavenging activity slightly increased when the heating time reached $50 \mathrm{~min}$. In the meanwhile, the chelating activity of coconut sap increased at the beginning of $20 \mathrm{~min}$ of heating.

\section{ACKNOWLEDGMENT}

This research was financially supported by the Ministry of Research, Technology and Higher Education through Research Capacity Building Program, Doctoral Dissertation Research in 2017 (No. 068/SP2H/LT/DRPM/IV/2017).

\section{REFERENCES}

1. Y. Asikin, A. Kamiya, M. Mizu, K. Takara, H. Tamaki and K. Wada, Food Chemistry, 149, 170(2014), DOI: 10.1016/j.foodchem.2013.10.089

2. N.A.M. Eskin and F. Shahidi, Biochemistry of Foods, Elsevier, London, p. 245, 254 (2013)

3. H. Nursten, The Maillard Reaction, The Royal Society of Chemistry, Reading, UK, p. 20 (2005)

4. B.B. Borse, L. Jagan, M. Rao, K. Ramalakshmi and B. Raghavan, Food Chemistry, 101, 877(2007), DOI:10.1016/j.foodchem.2006.02.026

5. T. Nagai, N. Kai, Y. Tanoue and N. Suzuki, Journal of Food Science and Technology, 55, 586(2018), DOI: 10.1007/s13197-017-2968-y

6. R.A. Carciochi, K. Dimitrov and L. Galván D'Alessandro, Journal of Food Science and Technology, 53, 3978(2016)

7. A.N. Wijewickreme, Z. Krejpcio and D.D. Kitts, Journal of Food Science, 64, 457(1999)

8. J.S. Kim, Food Science and Biotechnology, 22, 39(2013a), DOI:10.1007/s10068-013-0006-z

9. J.S. Kim, Food Science and Biotechnology, 22, 831(2013b), DOI:10.1007/s10068-013-0152-3

10. W. Jung, P. Park, C. Ahn and J. Je, Food Chemistry, 145, 173(2014), DOI:10.1016/j.foodchem.2013.08.042

11. F. Yan, X. Yu and Y. Jing, Journal of Food Science and Technology, 55, 712(2018), DOI:10.1007/s13197-017-2982-0

12. Karseno, Erminawati, T. Yanto, R. Setyawati and P. Haryanti, Food Research, 2, 32(2018), 
RASĀYAN J. Chem.

Vol. 13 | No. 3 |2010-2019| July - September | 2020

DOI:10.26656/fr.2017.2(1).175

13. S.B. Sulistyo and P. Haryanti, Food Research, 4, 976(2020), DOI: 10.26656/fr.2017.4(4).410

14. P. Haryanti, Supriyadi, DW. Marseno and U. Santoso, The International Journal Of Science \& Technoledge, 5, 52(2017)

15. G.L. Miller, Analitical Chemistry, 31, 426(1959)

16. L. Yao, L. Xu, Y. Jiang, N. Caffin, B. D'Arcy, R. Singanusong, N. Datta and Y. Xu, Food Chemistry, 94, 115(2006), DOI:10.1016/j.foodchem.2004.11.009

17. L. Wang, R. Xu, B. Hu, W. Li, Y. Sun, Y. Tu and X. Zeng, Food Chemistry, 123, 1259(2010), DOI:10.1016/j.foodchem.2010.05.063

18. R. Thippeswamy, K.G. Gouda, D. Rao, A. Martin and L. Gowda, Journal of Agricultural and Food Chemistry, 54, 7014(2006)

19. B. Payet, ASC. Sing and J. Smadja, Journal of Agricultural and Food Chemistry, 53, 10074(2005)

20. C.W. Ho, W.M. Wan Aida, M.Y. Maskat and H. Osman, Pakistan Journal of Biological Sciences, 11, 989(2008)

21. F. Ashrafi, AKE. Khneghahi, A. Karbasyan and M. Norouzi, International Journal of ChemTech Research, 3, 975(2011)

22. W.A. Mahmood, Mesopotamia Journal of Agriculture, 38, 1(2010)

23. I. Siddiqui, Rasayan Journal of Chemistry, 3, 255(2010)

24. J.S. Kim and Y.S. Lee, Food Science and Biotechnology, 19, 929(2010), DOI:10.1007/s10068-0100131-x

25. B. Cammerer, W. Jalyschko and L.W. Kroh, Journal of Agricultural and Food Chemistry, 50, 2083(2002)

26. L.C. Fernandez, M.M. Doval, A.M. Romero and M.A. Judis, International Journal of Applied Science and Technology, 4, 104(2014)

27. M. Kambatyrov, U. Nazarbek, P. Abdurazova, S. Nazarbekova and Y. Raiymbekov, Rasayan Journal of Chemistry, 13(3), 1308(2020), DOI:10.31788/ RJC.2020.1335729

28. N. Buchner, A. Krumbein, S. Rohn and L.W. Kroh, Rapid Communication in Mass Spectrometry, 20, 3229(2006), DOI: $10.1002 / \mathrm{rcm}$

29. S. Rohn, H.M. Rawel and J. Kroll, Journal of Agricultural and Food Chemistry, 52, 4725(2004), DOI:10.1021/jf0496797

30. K. Brudzynski and D. Miotto, Food Chemistry, 125, 570(2011), DOI:10.1016/j.foodchem.2010.09.049

31. F. Pellati, S. Benvenuti, L. Magro, M. Melegari and F. Soragni, Journal of Pharmaceutical and Biomedical Analysis, 35, 289(2004), DOI:10.1016/S0731-7085(03)00645-9

32. S. Atun, R. Arianingrum, L. Cahyaningsih F. A. Pratiwi, R. Kusumaningrum, and M. Khairuddean, Rasayan Journal of Chemistry, 13(3), 1347(2020), DOI:10.31788/ RJC.2020.1335868

33. H. Wang, H. Qian and W. Yao, Food Chemistry, 128, 573(2011), DOI:10.1016/j.foodchem.2011.03.075

34. J.A. Gomez-Ruiz, J.M. Ames and D.S. Leake, European Food Research and Technology, 227, 1017(2008), DOI: 10.1007/s00217-007-0815-5

35. F.J. Morales and S.J. Perez, European Food Research and Technology, 218, 515(2004), DOI:10.1007/s00217-004-0896-3

36. J.M. Silvan, J. Van de Lagemaat, A. Olano and M.D. del Castilo, Journal of Pharmaceutical and Biomedical Analysis, 41, 1543(2006), DOI:10.1016/j.jpba.2006.04.004

[RJC-5443/2020] 